\title{
FURTHER INVESTIGATIONS OF THE PASSIVE OPTICAL SAMPLE ASSEMBLY (POSA) - I FLIGHT EXPERIMENT
}

\author{
Miria M. Finckenor \\ Senior Member, AIAA \\ ED31 Environmental Effects \\ NASA - Marshall Space Flight Center \\ Marshall Space Flight Center, AL 35812 \\ Phone (256) 544-9244 \\ Fax (256) 544-0212 \\ Rachel R. Kamenetzky \\ ED31 Environmental Effects \\ NASA - Marshall Space Flight Center \\ Marshall Space Flight Center, AL 35812 \\ Phone (256) 544-1089 \\ Fax (256) 544-0212 \\ rachel.kamenetzky@msfc.nasa.gov
}

\author{
Jason A. Vaughn \\ ED31 Environmental Effects \\ NASA - Marshall Space Flight Center \\ Marshall Space Flight Center, AL 35812 \\ Phone (256) 544-9347 \\ Fax (256) 544-5013 \\ jason.vaughn@msfc.nasa.gov \\ Richard Mell \\ AZ Technology \\ 7047 Old Madison Pike Suite 300 \\ Huntsville, AL 35806 \\ Phone (256) 837-9877 x 131 \\ Fax (256) 837-1155 \\ M. S. Deshpande \\ IIT Research Institute \\ 10 West $35^{\text {th }} \mathrm{St}$. \\ Chicago, IL 60616
}

The Passive Optical Sample Assembly-I (POSA-I), part of the Mir Environmental Effects Payload (MEEP), was designed to study the combined effects of contamination, atomic oxygen, ultraviolet radiation, vacuum, thermal cycling, and other constituents of the space environment on spacecraft materials. The MEEP program is a Phase 1 International Space Station Risk Mitigation Experiment.

Candidate materials for the International Space Station (ISS) were exposed in a specially designed "suitcase" carrier, with identical specimens facing either Mir or space. The payload was attached by EVA to the exterior of the Mir docking module during the STS-76 mission (fig. 1). It was removed during the STS-86 mission after an 18-month exposure. During the mission, it received approximately $7 \times 10^{19}$ atoms $/ \mathrm{cm}^{2}$ atomic oxygen, as calculated by polymer mass loss, and 413 ESH of solar ultraviolet radiation on the Mir-facing side. The side facing away from Mir received significant contaminant deposition, so atomic oxygen fluence has not been reliably determined. The side facing away from Mir received $571 \mathrm{ESH}$ of solar UV.

Contamination was observed on both the Mir-facing and space-facing sides of the POSAI experiment ${ }^{1}$, with a greater amount of deposition on the space-facing side than the Mir-facing side. The contamination has been determined to be outgassed silicone photofixed by ultraviolet radiation and converted to silicate by atomic oxygen interaction. Electron spectroscopy for chemical analysis (ESCA) with depth profiling indicated the presence of $26-31 \mathrm{~nm}$ silicate on the Mir-facing side and $500-1000 \mathrm{~nm}$ silicate on the space-facing side. The depth profiling also showed that the contaminant layer was uniform, with a small amount of carbon present on the surface and trace amounts of nitrogen, phosphorus, sulfur, and tin. The surface carbon layer is 
likely due to post-flight exposure in the laboratory and is similar to carbonaceous deposits on control samples. EDAX and FTIR analysis concurred with ESCA for the presence of silicon, oxygen, and carbon.

Nearly 400 samples were exposed on POSA-I, which included materials such as thermal control coatings, polymeric films, optical materials, and multi-layer insulation blankets. A previous paper ${ }^{2}$ discussed the effects of the space environment exposure and contaminant deposition on candidate materials for ISS, including Z93P inorganic thermal control coating, various anodizes, and multi-layer insulation blankets. This paper details the investigation of environmental effects on the remainder of POSA-I samples, particularly the innovative conductive thermal control coatings developed by AZ Technology of Huntsville, AL and IIT Research Institute of Chicago, IL. The silicone/silicate contamination had a significant impact on the solar absorptance of white inorganic thermal control coatings on the space-facing side of POSA-I (fig. 2). The effect of contamination on electrical conductivity is discussed.

Samples of conductive anodized aluminum developed by Boundary Technologies of Buffalo Grove, IL were also exposed on POSA-I. The effects of the space environment and contaminant deposition on the optical and electrical properties of the conductive anodized aluminum are discussed.

\section{References}

1. "Contamination observed on the Passive Optical Sample Assembly (POSA) -I experiment", by James M. Zwiener, Rachel R. Kamenetzky, Jason A. Vaughn, and Miria M. Finckenor, SPIE International Symposium on Optical Science, Engineering, and Instrumentation, San Diego, CA, July 1998, SPIE paper \# 3427A-20.

2. "The Passive Optical Sample Assembly (POSA) - I Experiment: First Flight Results and Conclusions", by James M. Zwiener, Rachel R. Kamenetzky, Jason A. Vaughn, and Miria M. Finckenor, AIAA Aerospace Sciences Meeting, Reno, NV, Jan. 1999, AIAA paper \#990104 . 


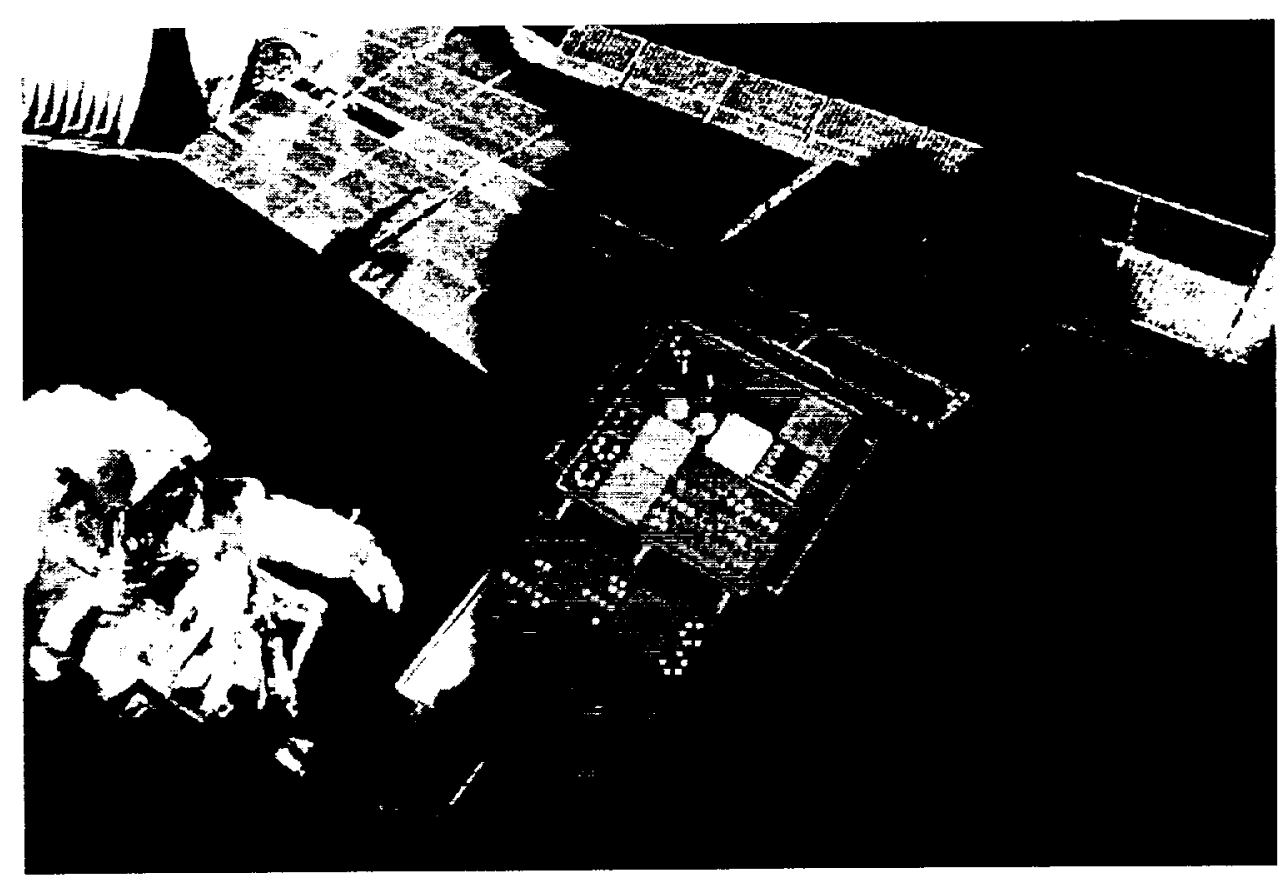

Figure 1 POSA-I deployed on Mir space station

\section{AZ White Conductive Paint}

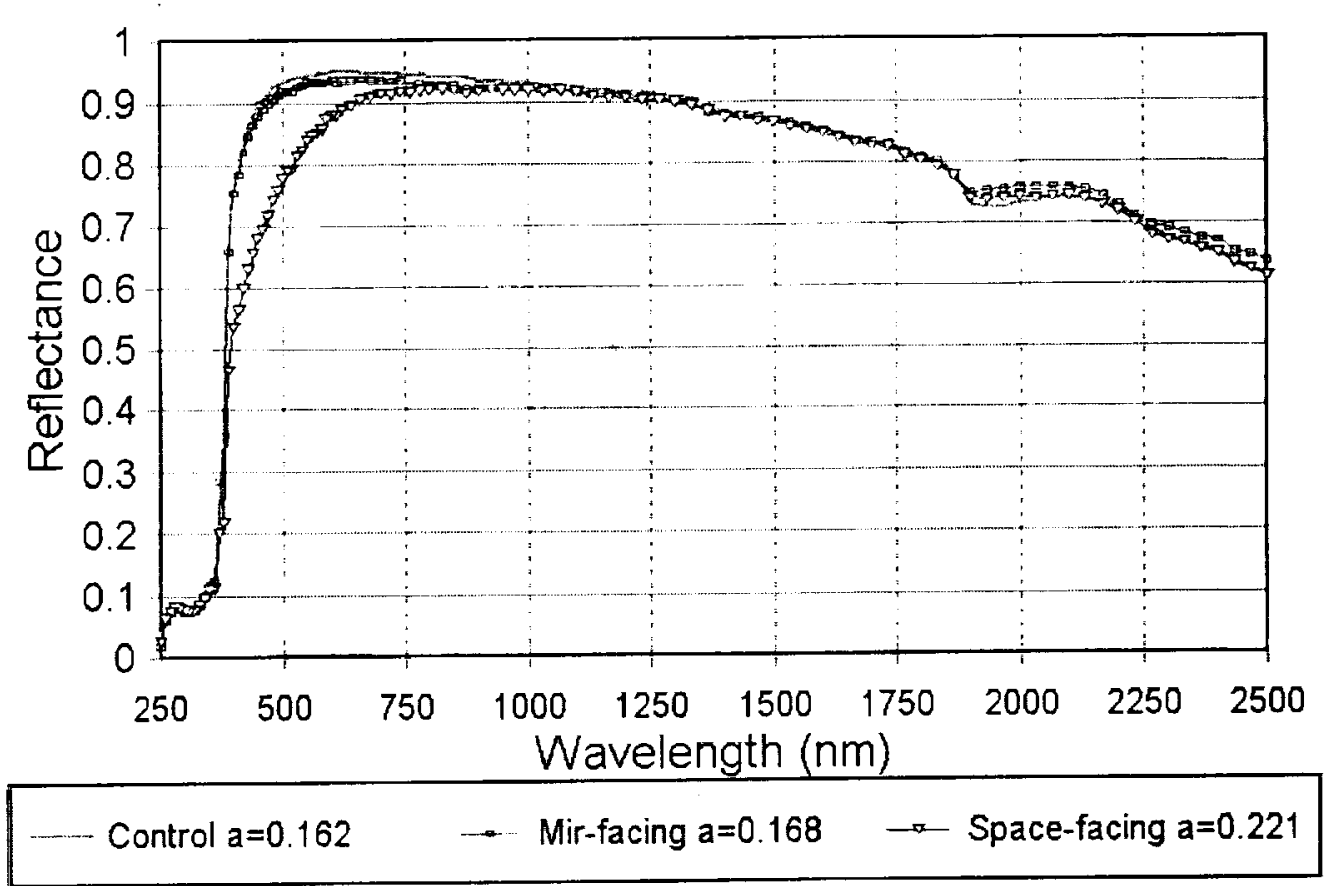

Figure 2 